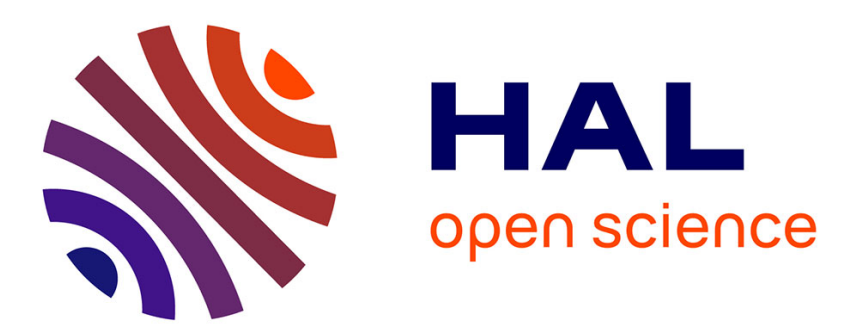

\title{
Model reduction of converters for the analysis of $100 \%$ power electronics transmission systems
}

Quentin Cossart, Frédéric Colas, Xavier Kestelyn

\section{To cite this version:}

Quentin Cossart, Frédéric Colas, Xavier Kestelyn. Model reduction of converters for the analysis of $100 \%$ power electronics transmission systems. 2018 IEEE International Conference on Industrial Technology (ICIT), 2018, Lyon, France. pp.1254 - 1259, 10.1109/ICIT.2018.8352358 . hal-03170511

\section{HAL Id: hal-03170511 \\ https://hal.science/hal-03170511}

Submitted on 16 Mar 2021

HAL is a multi-disciplinary open access archive for the deposit and dissemination of scientific research documents, whether they are published or not. The documents may come from teaching and research institutions in France or abroad, or from public or private research centers.
L'archive ouverte pluridisciplinaire HAL, est destinée au dépôt et à la diffusion de documents scientifiques de niveau recherche, publiés ou non, émanant des établissements d'enseignement et de recherche français ou étrangers, des laboratoires publics ou privés. 


\title{
Model Reduction of Converters for the Analysis of 100\% Power Electronics Transmission Systems
}

\author{
Quentin Cossart, Frédéric Colas, Xavier Kestelyn \\ Univ. Lille 1, Centrale Lille, Arts et Métiers ParisTech, HEI, \\ EA 2697-L2EP-Laboratoire d'Electrotechnique et d'Electronique de Puissance \\ F-59000 Lille, France \\ quentin.cossart@ensam.eu
}

\begin{abstract}
Because of the fast development of wind and solar photovoltaic power plants, as well as the multiplication of high voltage direct current links, the analysis and simulation of large transmission systems with a high penetration of power electronic converters have become necessary. In this situation, reduced models of converters are needed to make the simulation faster and the stability analysis more straightforward. These reduced models need to be accurate enough, depending on the needed accuracy, and they have to keep the physical structure of the converter full model to be easily implemented on classical analysis software. A structure-preserving method to reduce the state order of a grid forming converter model is presented here. It is based on a modal analysis to remove the fastest poles of the system while keeping the slowest almost unchanged.
\end{abstract}

Keywords-model order reduction; power system simulation; power electronics converters; stability analysis

\section{INTRODUCTION}

The fast development of renewable energies [1] and high voltage direct current links increases the penetration of Power Electronics (PE) while decreasing the penetration of Synchronous Machines (SM) in the electric transmission system [2]. PE converters and SM have different physical behaviors. PE converters have no inertia [3] and they cannot handle high transient currents unlike SM [4]. As a result, issues can happen in the transmission systems when the penetration of PE becomes too important [5]. For now, PE converters have been controlled as grid feeding converters [6]. They inject power into an existing stiff grid. Keeping only grid feeding inverters seems not reliable if the penetration of PE keeps on increasing. New ways of controlling PE converters are needed. With grid forming converters, the voltage waveform is created by the converter, just like would a SM do [7].

Because of the size and the complexity of the transmission systems, real scale experiments on large systems are not possible and numerical simulations are needed to validate new controls. Today, two types of programs exist to simulate power systems. Electromagnetic transient (EMT) programs [8] model the system in a detailed way, leading to precise but timeconsuming simulations. They are mainly used for local studies. Transient Stability Programs (TSP) simplify the models by neglecting some electromagnetic dynamics, as they are faster than the electromechanical dynamics of SM, to simulate large systems. It is often called the phasor approximation [9]. In the case of a $100 \%$ PE power system, phasor programs are not adequate as there are no more electromechanical dynamics. On the other hand, EMT models are detailed and complex, which leads to high computation times [10] and complicated analysis. As a consequence, finding simplified models, like with the phasor approximation, but adapted to power electronics studies, is necessary [11].

The process to compute simplified models is called Model Order Reduction (MOR). Several methods exist [12], such as the Balanced Truncation [13], the Proper Orthogonal Decomposition (POD) [14], the Hankel-norm approximation [15] or the Lanczos and Arnoldi procedures [16]. But because they use projections and truncations, these methods modify the physical structure of the system and the state variables. This results in not flexible simulation and analysis, since the modeling has to be done again before each new simulation.

In this paper, a MOR method adapted to the analysis of power systems with $100 \% \mathrm{PE}$ is proposed in order to have faster simulation of large transmission systems. Unlike the other existing methods, it preserves the physical structure while keeping some variables of the system, which makes the simulation and analysis more flexible: only a few things have to be changed before each new simulation. This method uses modal analysis [17] tools, such as the participation factors [18], to analyze the poles of the system and derive reduced models.

The second part of this paper will describe the method, the third one the considered grid forming converter and the fourth one the results of the application of the method to the selected example.

\section{DESCRIPTION OF THE PROPOSED MODEL ORDER REDUCTION METHOD}

The proposed MOR method takes a linearization of the model and removes its fastest eigenvalues (far from the imaginary axis) by simply freezing some state variables dynamics, making the MOR more flexible than with the existing methods. This results in a reduced system with the slow eigenvalues only (close to the imaginary axis). This method will be presented with more details in this section.

\section{A. Linearization of the model}

We consider a nonlinear differential algebraic system which can be represented by (1) and (2). 


$$
\begin{aligned}
\frac{d x}{d t} & =f(x, y, u) \\
0 & =g(x, y, u)
\end{aligned}
$$

It is linearized around an operating point in (3) and (4).

$$
\begin{gathered}
\frac{d \Delta x}{d x}=A \Delta x+B \Delta y+C \Delta u \\
0=D \Delta x+E \Delta y+F \Delta u
\end{gathered}
$$

If $E$ is not singular, it can then be written in a state space formulation as in (5), (6) and (7).

$$
\begin{gathered}
\frac{d \Delta x}{d x}=A_{s s} \Delta x+B_{s s} \Delta u \\
A_{s s}=A-B E^{-1} D \\
B_{s s}=C-B E^{-1} F
\end{gathered}
$$

\section{B. Calculation of the participation factors}

The idea of this MOR method is to remove the fast eigenvalues of the system while keeping the slow ones almost unchanged, by freezing some state variables dynamics. To do that, the participation factors of the system are needed [18]. The participation of a state variable in an eigenvalue is defined as its influence on this eigenvalue. The participation factors give the participation of each state variable in each eigenvalue. The participation of $\Delta x_{j}$ in $\lambda_{i}$ an eigenvalue of the state matrix $A_{s s}$ is defined by (8).

$$
P_{i, j}=u_{i, j} y_{i, j}
$$

where $y_{i, j}$ is the $j^{\text {th }}$ entry of the $i^{\text {th }}$ right eigenvector of $A_{s s}$ and $u_{i, j}$ is the $j^{\text {th }}$ entry of the $i^{t h}$ left eigenvector of $A_{s s}$. With this, it is possible to know, for each eigenvalue, which state variables participate the most in it. The same way, it is possible to know in which eigenvalues a state variable participates.

\section{Freezing of the neglected dynamics}

Let's consider an eigenvalue $\lambda_{i}$. Its participation factors show that the state variable $\Delta x_{j}$ participates more than the other state variables in $\lambda_{i}\left(P_{i, j}>10 P_{i, k}, \forall k \neq j\right)$. To delete $\lambda_{i}$ the differential equation (9) of $x_{j}$ in the nonlinear model is changed into an algebraic equation (10).

$$
\begin{gathered}
\frac{d x_{j}}{d t}=f_{j}(x, y, u) \\
0=f_{j}(x, y, u)
\end{gathered}
$$

The idea is to do it for all the eigenvalues that are considered to be fast enough to be neglected. It is important to note that several states can participate in an eigenvalue and that each state can participate in several eigenvalues.

\section{GRID FORMING CONVERTER MODEL [19]}

The presented MOR method will be tested on the grid forming converter presented in this section. Its structure is given in figure 1, its control is presented with block diagrams in figures $2-5$ and then the system equations are given in equations (11)-(33).

\section{A. General structure}

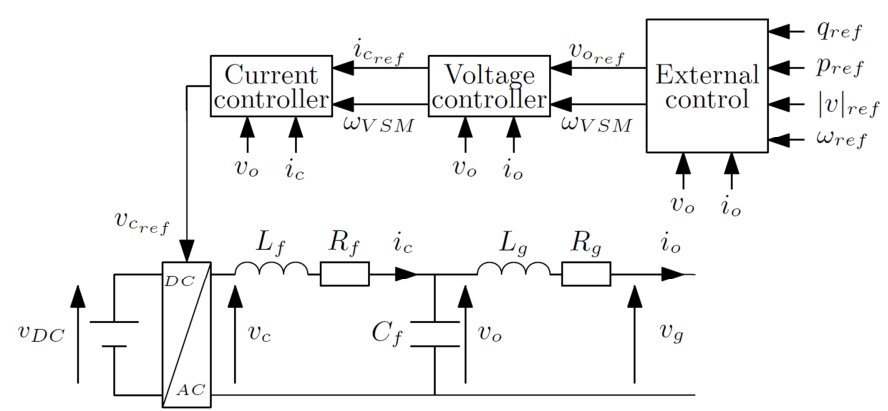

Fig. 1. General structure of the grid forming converter

This grid forming converter is made of a DC source, the converter itself, an RLC filter and an RL line (this can also represent a transformer). Its control is made of an external control composed of a reactive power droop and a Virtual Synchronous Machine (VSM), and an internal control composed of a voltage control and a current control. These parts are described in the following subsections.

\section{B. External control}

The external control is made of a reactive power droop and a VSM, as shown in figures 2 and 3.

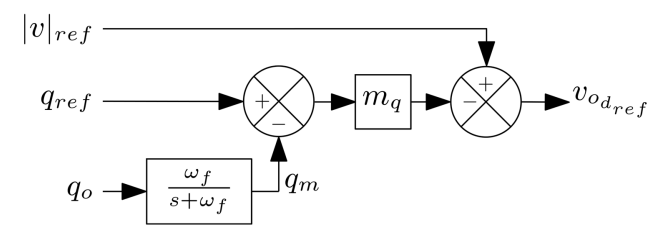

Fig. 2. Reactive power droop

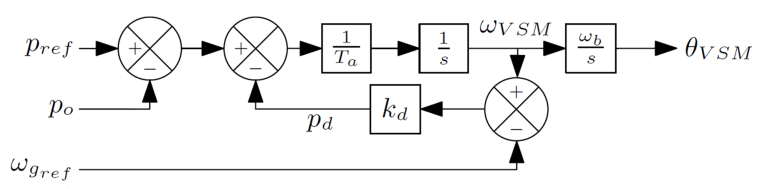

Fig. 3. Virtual synchronous machine

\section{Internal control}

The current and voltage controls are classical dq-controllers as described in figures 4 and 5. They are cascaded loops and use two PI controllers each.

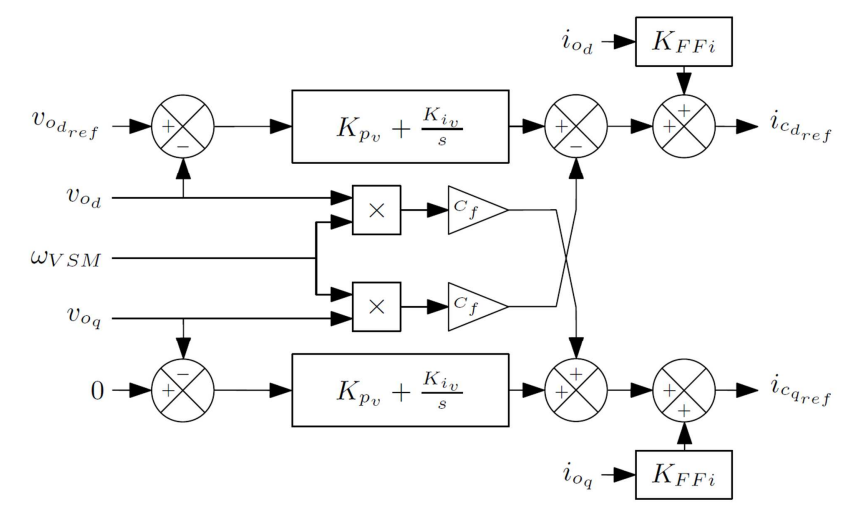

Fig. 4. Voltage control 


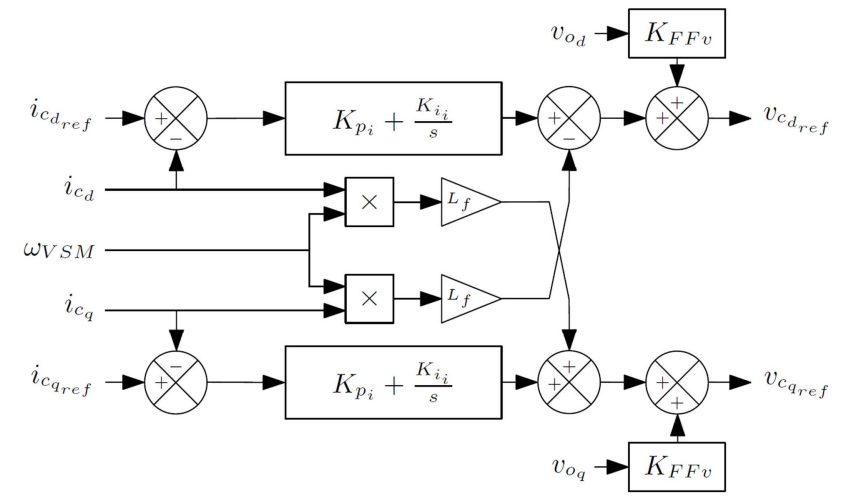

Fig. 5. Current control

\section{System equations}

The system can also be described by its differential and algebraic equations, which are given in this subsection. It has 13 differential equations and 10 algebraic equations.

$$
\begin{aligned}
& \frac{L_{f}}{\omega_{b}} \frac{d i_{c_{d}}}{d t}=v_{c_{d}}-v_{o_{d}}-R_{f} i_{c_{d}}+\omega_{V S M} L_{f} i_{c_{q}} \\
& \frac{L_{f}}{\omega_{b}} \frac{d i_{c_{q}}}{d t}=v_{c_{q}}-v_{o_{q}}-R_{f} i_{c_{q}}-\omega_{V S M} L_{f} i_{c_{d}} \\
& \frac{C_{f}}{\omega_{b}} \frac{d v_{o_{d}}}{d t}=i_{c_{d}}-i_{o_{d}}+\omega_{V S M} C_{f} v_{o_{q}} \\
& \frac{C_{f}}{\omega_{b}} \frac{d v_{o q}}{d t}=i_{c_{q}}-i_{o_{q}}-\omega_{V S M} C_{f} v_{o_{d}} \\
& \frac{L_{g}}{\omega_{b}} \frac{d i_{o_{d}}}{d t}=v_{o_{d}}-v_{g_{d}}-R_{g} i_{o_{d}}+\omega_{V S M} L_{g} i_{o_{q}} \\
& \frac{L_{g}}{\omega_{b}} \frac{d i_{o q}}{d t}=v_{o_{q}}-v_{g_{q}}-R_{g} i_{o_{q}}-\omega_{V S M} L_{g} i_{o_{d}} \\
& p_{o}=v_{o_{d}} i_{o_{d}}+v_{o_{q}} i_{o_{q}} \\
& q_{o}=v_{o_{q}} i_{o_{d}}-v_{o_{d}} i_{o_{q}} \\
& T_{a} \frac{d \omega_{v s m}}{d t}+k_{d}\left(\omega_{v s m}-\omega_{g_{r e f}}\right)=p_{r e f}-p_{o} \\
& \frac{1}{\omega_{b}} \frac{d \theta_{V S M}}{d t}=\omega_{V S M} \\
& \frac{d q_{m}}{d t}+\omega_{f} q_{m}=\omega_{f} q_{o} \\
& v_{o_{\text {ref }}}=|v|_{\text {ref }}-m_{q}\left(q_{\text {ref }}-q_{m}\right) \\
& \frac{d \xi_{d}}{d t}=K_{i_{v}}\left(v_{o_{d_{r e f}}}-v_{o_{d}}\right) \\
& \frac{d \xi_{q}}{d t}=K_{i_{v}}\left(v_{o_{q_{\text {ref }}}}-v_{o_{q}}\right) \\
& i_{c_{d_{r e f}}}=K_{F F_{i}} i_{o_{d}}+K_{p_{v}}\left(v_{o_{d_{r e f}}}-v_{o_{d}}\right)-\omega_{V S M} C_{f} v_{o_{q}}+\xi_{d} \\
& i_{c_{q_{r e f}}}=K_{F F_{i}} i_{o_{q}}+K_{p_{v}}\left(v_{o_{q_{r e f}}}-v_{o_{q}}\right)+\omega_{V S M} C_{f} v_{o_{d}}+\xi_{q} \\
& \frac{d \sigma_{d}}{d t}=K_{i_{i}}\left(i_{c_{d_{r e f}}}-i_{c_{d}}\right) \\
& \frac{d \sigma_{q}}{d t}=K_{i_{i}}\left(i_{c_{q_{r e f}}}-i_{c_{q}}\right) \\
& v_{c_{d_{r e f}}}=K_{F F_{v}} v_{o_{d}}+K_{p_{i}}\left(i_{c_{d_{r e f}}}-i_{c_{d}}\right)-\omega_{V S M} L_{f} i_{c_{q}}+\sigma_{d}
\end{aligned}
$$

$$
\begin{gathered}
v_{c_{q_{r e f}}}=K_{F F_{v}} v_{o_{q}}+K_{p_{i}}\left(i_{c_{q_{r e f}}}-i_{c_{q}}\right)+\omega_{V S M} L_{f} i_{c_{d}}+\sigma_{q} \\
v_{c_{d_{r e f}}}=v_{c_{d}} \\
v_{c_{q_{r e f}}}=v_{c_{q}} \\
v_{o_{q_{r e f}}}=0
\end{gathered}
$$

IV. APPLICATION OF THE MODEL ORDER REDUCTION METHOD TO A GRID FORMING CONVERTER MODEL

The converter that has been presented in the previous section is considered with the parameters in table I [19] :

\begin{tabular}{|c|c|c|c|c|c|}
\hline$|v|_{r e f}$ & 1 & $p_{r e f}$ & 0.4 & $q_{r e f}$ & 0 \\
\hline$R_{f}$ & 0.003 & $L_{f}$ & 0.1 & $C_{f}$ & 0.2 \\
\hline$R_{g}$ & 0.003 & $L_{g}$ & 0.1 & $\omega_{b}$ & $314 \mathrm{rad} / \mathrm{s}$ \\
\hline$K_{F F_{v}}$ & 1 & $K_{p_{i}}$ & 0.6366 & $K_{i_{i}}$ & 20 \\
\hline$K_{F F_{i}}$ & 0 & $K_{p_{v}}$ & 1.795 & $K_{i_{v}}$ & 80.79 \\
\hline$k_{d}$ & 3110 & $T_{a}$ & $2 \mathrm{~s}$ & $\omega_{g_{r e f}}$ & 1 \\
\hline$m_{q}$ & 0.00004 & $\omega_{f}$ & 31.42 & & \\
\hline
\end{tabular}

\section{A. Participation factors and general principle}

The method previously described is applied to the converter. First, the whole system is linearized around its operating point, which gives a $13^{\text {th }}$ order linear system like in (5), with 13 eigenvalues (see Table II). The next step is to determine the participation factors of each state variable in each eigenvalue. It is done using the equation (8). An example is given in figure 6 .

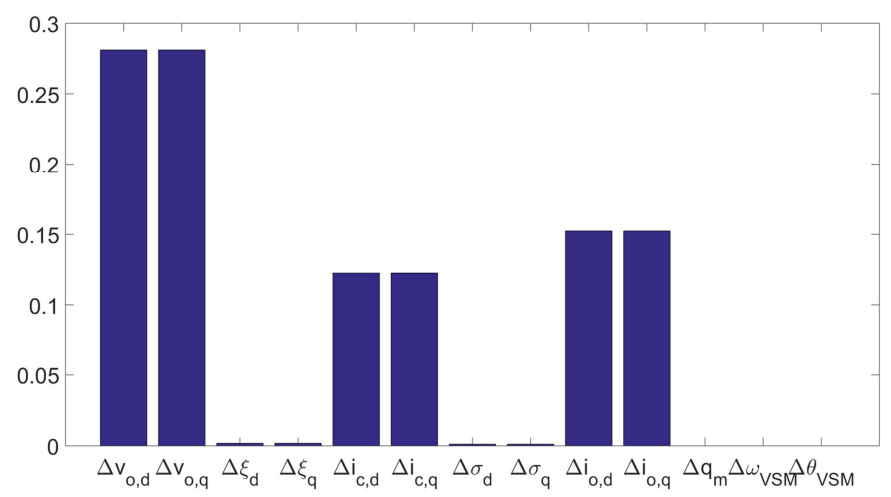

Fig. 6. Participation factors of $\lambda_{9,10}$

This example shows that this double eigenvalue almost exclusively depends on the dynamics of the voltages and currents in the system. The same job is done for each eigenvalue, and they are then grouped depending on their dependence, as shown in table II. It can be seen that each state variable influences several eigenvalues and that each eigenvalue depends on several state variables. 
TABLE II. GROUPS OF EIGENVALUES DEPENDING ON THEIR PARTICIPATION FACTORS

\begin{tabular}{|c|c|c|}
\hline Eigenvalues & State variables & Model order \\
\hline$\lambda_{13}=-1555$ & $\omega_{V S M}$ & 12 \\
\hline$\lambda_{11,12}=-1048 \pm 179 i$ & $v_{o d}, v_{o q}, i_{o d}$ & 6 \\
$\lambda_{9,10}=-507 \pm 3290 i$ & $i_{o q}, i_{c d}, i_{c q}$ & \\
$\lambda_{7,8}=-430 \pm 2849 i$ & & 4 \\
\hline$\lambda_{5,6}=-31.76 \pm 0.02 i$ & $\sigma_{d}, \sigma_{q}$ & 3 \\
\hline$\lambda_{4}=-31.4$ & $q_{m}$ & NA \\
\hline$\lambda_{2,3}=-1.03 \pm 7.7 i$ & $\xi_{d}, \xi_{q}, \theta_{V S M}$ & \\
$\lambda_{1}=-1$ & & \\
\hline
\end{tabular}

From this table, four reduced models can be obtained, allowing deleting the fastest eigenvalues while keeping the slow ones untouched:

- A $12^{\text {th }}$ order model, without $\lambda_{13}$, by neglecting the dynamic of $\omega_{V S M}$;

- A $6^{\text {th }}$ order model, without $\lambda_{13}, \lambda_{11,12}, \lambda_{9,10}$ and $\lambda_{7,8}$ by neglecting the dynamic of $\omega_{V S M}, v_{o d}, v_{o q}, i_{o d}, i_{o q}, i_{c d}$ and $i_{c q}$;

- A $4^{\text {th }}$ order model, without $\lambda_{13}, \lambda_{11,12}, \lambda_{9,10}, \lambda_{7,8}$ and $\lambda_{5,6}$ by neglecting the dynamic of $\omega_{V S M}, v_{o d}, v_{o q}, i_{o d}, i_{o q}, i_{c d}, i_{c q}$, $\sigma_{d}$ and $\sigma_{q}$;

- A $3^{r d}$ order model, without $\lambda_{13}, \lambda_{11,12}, \lambda_{9,10}, \lambda_{7,8}, \lambda_{5,6}$ and $\lambda_{4}$ by neglecting the dynamic of $\omega_{V S M}, v_{o d}, v_{o q}, i_{o d}, i_{o q}, i_{c d}$, $i_{c q}, \sigma_{d}, \sigma_{q}$ and $q_{m}$;

\section{B. $12^{\text {th }}$ order model}

The $12^{\text {th }}$ order model is obtained by changing equation (19) into equation (34).

$$
k_{d}\left(\omega_{v s m}-\omega_{g}\right)=p_{r e f}-p_{o}
$$

Figures 7 and 8 show how the VSM is physically modified by the MOR.

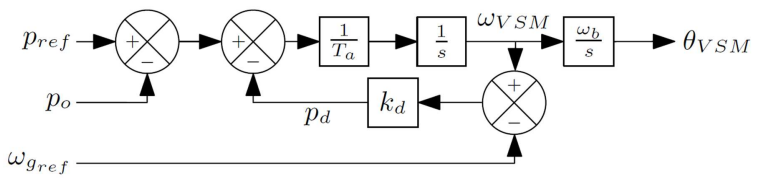

Fig. 7. Virtual Synchronous Machine before the MOR

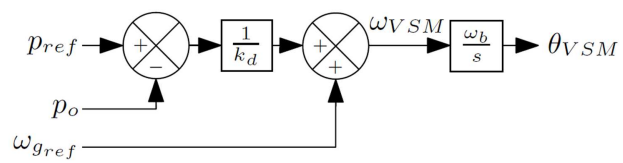

Fig. 8. Virtual Synchronous Machine after the MOR

It can be seen that with this kind of MOR, the physical structure of the system is kept, it is possible to represent the reduced system with a block diagram close to the full system.

\section{C. $6^{\text {th }}$ order model}

For the $6^{\text {th }}$ order model, the eigenvalue $\lambda_{13}$ is removed like in the $12^{\text {th }}$ order model. The eigenvalues $\lambda_{11,12}, \lambda_{9,10}$ and $\lambda_{7,8}$ are also deleted by freezing the dynamics of the currents and voltages in the system. Equations (11)-(16) are changed into equations (35)-(40).

$$
\begin{aligned}
0= & v_{c_{d}}-v_{o_{d}}-R_{f} i_{c_{d}}+\omega_{V S M} L_{f} i_{c_{q}} \\
0= & v_{c_{q}}-v_{o_{q}}-R_{f} i_{c_{q}}-\omega_{V S M} L_{f} i_{c_{d}} \\
& 0=i_{c_{d}}-i_{o_{d}}+\omega_{V S M} C_{f} v_{o_{q}} \\
& 0=i_{c_{q}}-i_{o_{q}}-\omega_{V S M} C_{f} v_{o_{d}} \\
0= & v_{o_{d}}-v_{g_{d}}-R_{g} i_{o_{d}}+\omega_{V S M} L_{g} i_{o_{q}} \\
0= & v_{o_{q}}-v_{g_{q}}-R_{g} i_{o_{q}}-\omega_{V S M} L_{g} i_{o_{d}}
\end{aligned}
$$

This approximation is similar to the phasor approximation that is made in the TSP.

\section{D. $4^{\text {th }}$ order model}

For the $4^{\text {th }}$ order model, the eigenvalues $\lambda_{13}, \lambda_{11,12}, \lambda_{9,10}$ and $\lambda_{7,8}$ are removed like in the $6^{\text {th }}$ order model, but also $\lambda_{5,6}$ by simplifying the current control equations. Equations (27) and (28) are changed into equations (41) and (42).

$$
\begin{aligned}
& i_{c_{d_{r e f}}}=i_{c_{d}} \\
& i_{c_{q_{\text {ref }}}}=i_{c_{q}}
\end{aligned}
$$

Figures 9 and 10 show the modification induced by the MOR in the current control.

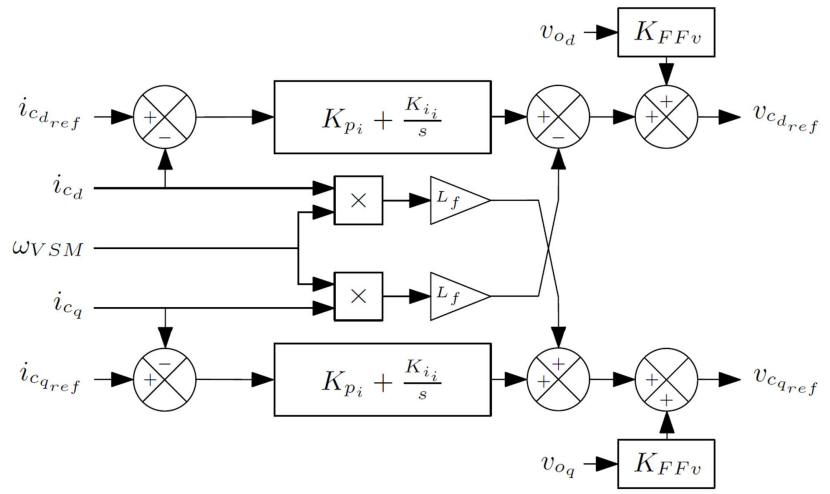

Fig. 9. Current control before the MOR

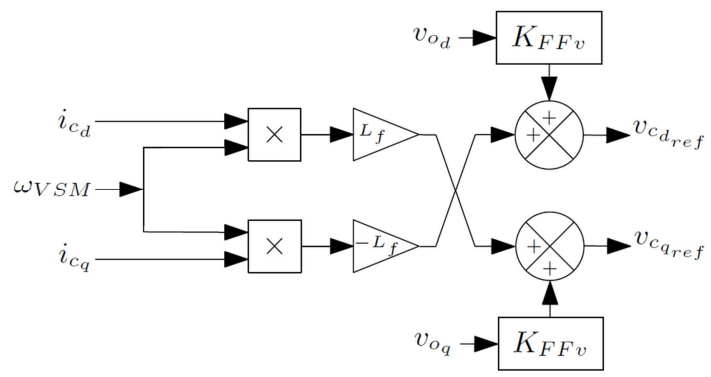

Fig. 10. Current control after the MOR

\section{E. $3^{\text {rd }}$ order model}

For the $3^{\text {rd }}$ order model, the eigenvalues $\lambda_{13}, \lambda_{11,12}, \lambda_{9,10}$, $\lambda_{7,8}$ and $\lambda_{5,6}$ are removed like in the $4^{\text {th }}$ order model, but also $\lambda_{4}$ by simplifying the reactive power droop equation. Equation (21) becomes equation (43).

$$
q_{m}=q_{o}
$$

Figures 11 and 12 show the modification induced by the MOR in the reactive power droop. 


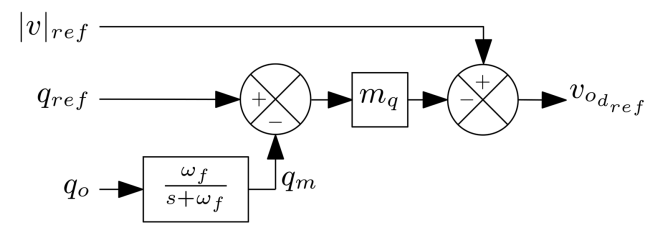

Fig. 11. Reactive power droop before the MOR

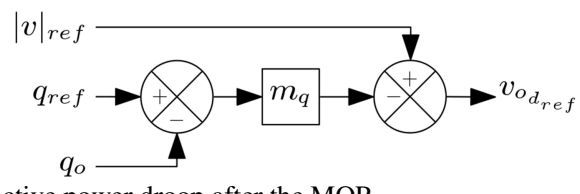

Fig. 12. Reactive power droop after the MOR

\section{$F$. Comparison of the eigenvalues of the full and reduced models}

To check the stability, a pole analysis is done. Figures 13 and 14 compare the eigenvalues of the different models. As wanted, the fast eigenvalues are deleted and the slow ones are kept the same. Because the slow eigenvalues (that are close to the imaginary axis and could become unstable if some parameters change) are kept exactly the same, it is sure that the stability is kept.

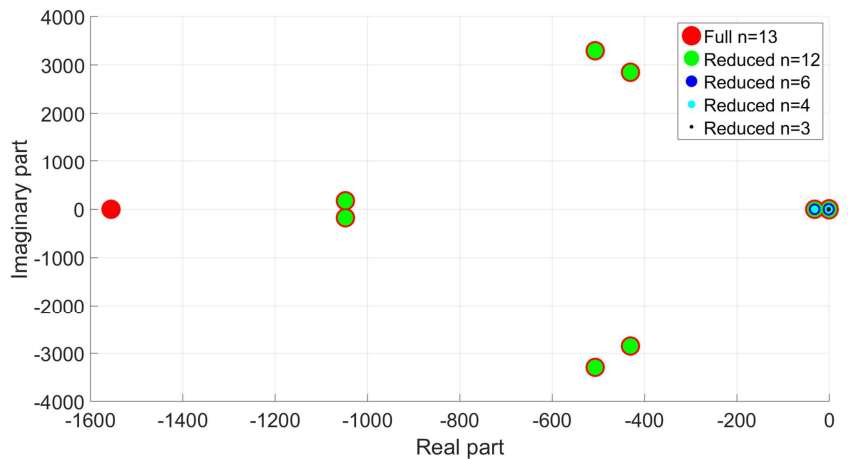

Fig. 13. Eigenvalues of the full and reduced models

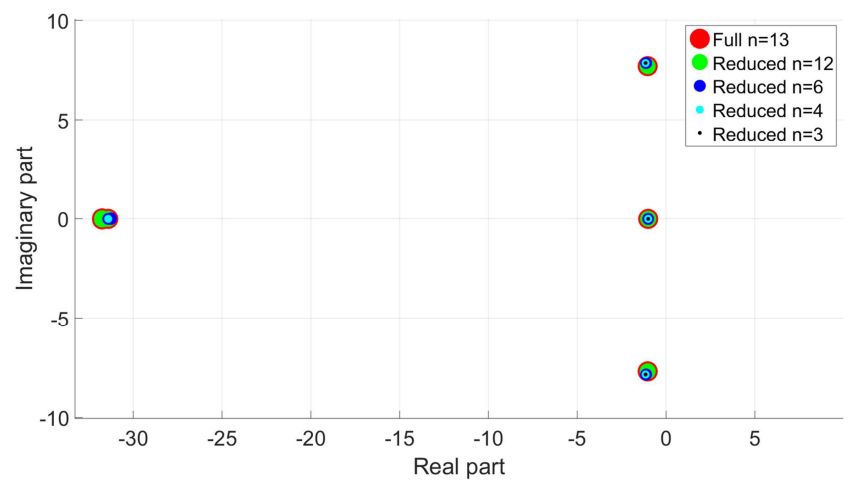

Fig. 14. Eigenvalues of the full and reduced models (zoom)

\section{G. Comparisons of the full and reduced models with time simulations}

To validate the reduced models, time-domain simulations are then necessary. The grid forming converter is connected to an infinite grid through two lines in parallel as shown in figure 15. A short-circuit happens in the middle of a line and is cleared by its tripping $100 \mathrm{~ms}$ after the fault.

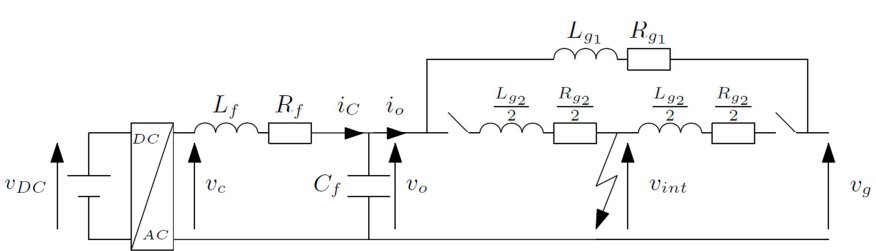

Fig. 15. System under consideration

This case is simulated with all the models (the full and the reduced ones) and the evolution of the active power at the Point of Common Coupling (PCC) is given in figures 16 and 17.

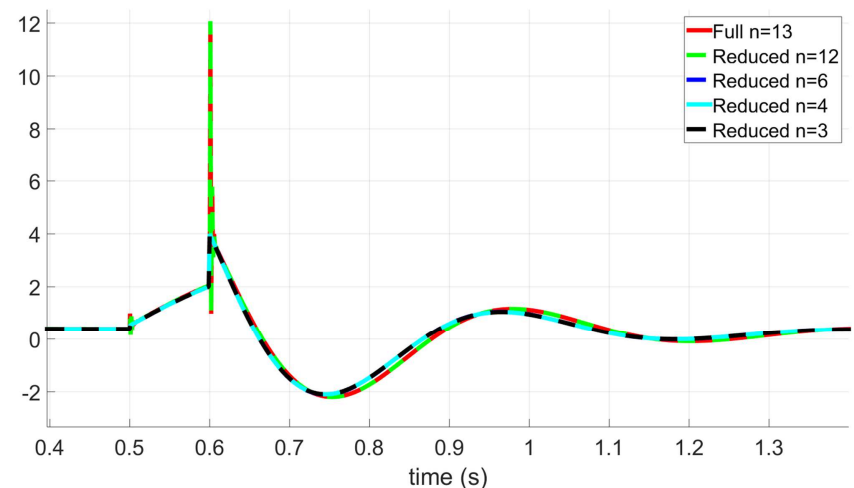

Fig. 16. Evolution of the active power at the PCC

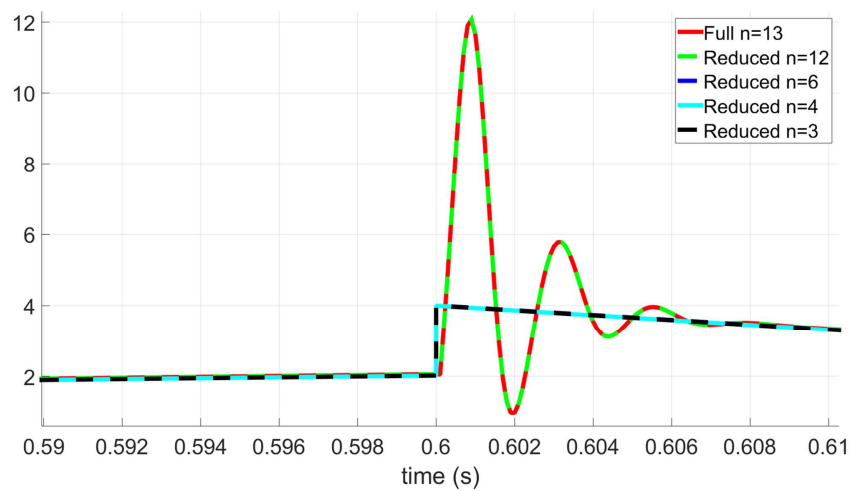

Fig. 17. Evolution of the active power at the PCC (zoom)

The general shapes of the curves are similar but there is an error when fast transients happen. To quantify this error, two indicators are defined:

$$
\begin{aligned}
\varepsilon_{1} & =\frac{1}{t_{f}} \int_{0}^{t_{f}}\left|p_{\text {ofull }}-p_{\text {oreduced }}\right| d t \\
\varepsilon_{2} & =\max \left(\left|p_{\text {ofull }}-p_{\text {oreduced }}\right|\right)
\end{aligned}
$$

The first indicator is an average error whereas the second one is a peak error. Table III gives the error for each reduced model.

The $12^{\text {th }}$ order model is the most accurate one, both in average and in peak, but it is not reduced enough to be considered as a real reduced model.

The other reduced models are less precise in peak but give good results in terms of average error. These $6^{\text {th }}, 4^{\text {th }}$ and $3^{\text {rd }}$ order models all give approximately the same accuracy. As a consequence, the $3^{\text {rd }}$ order one is the most interesting because it is the simplest. Its peak error is big, which can be a problem for overcurrent dimensioning studies, but not for stability studies. 
TABLE III. ERROR INDICATOR 1 AND 2 FOR EACH REDUCED MODEL (IN PU)

\begin{tabular}{|c|c|c|}
\hline Model order & $\varepsilon_{1}$ & $\varepsilon_{2}$ \\
\hline 12 & $2 e^{-4}$ & $1 e^{-3}$ \\
\hline 6 & $2.15 e^{-2}$ & 8.032 \\
\hline 4 & $2.17 e^{-2}$ & 8.033 \\
\hline 3 & $2.17 e^{-2}$ & 8.033 \\
\hline
\end{tabular}

\section{CONCLUSION AND PERSPECTIVES}

A MOR method using the modal analysis has been presented and applied to a grid forming converter in this paper. It simplifies the model by freezing some dynamics. The dynamics to freeze are chosen using mathematical tools such as participation factors, in order to delete the fast eigenvalues of the linearized system. The presented method, besides leading to faster simulations, keeps the physical structure of the system, which makes the analysis of large power systems with several test cases more convenient.

This paper has focused on a single grid forming converter connected to the grid and the results show that the stability is kept and the average error is small. The next step is to simulate large power systems with reduced converter models and compare it to the case with detailed converter models. As the MOR is done for each converter separately (this is called a Cartesian approach) one can wonder if some important interactions between different converters are missed during the process. It is possible that some fast eigenvalues of two different converters interact with each other and create a slow pole that would be missed, which can be tricky. As a consequence, a comparison with a systemic approach needs to be done. This will be the topic of a further study.

\section{ACKNOWLEDGMENT}

This work is part of the MIGRATE project (Massive InteGRATion of power Electronic devices). This project has received funding from the European Union's Horizon 2020 research and innovation programme under grant agreement No 691800.

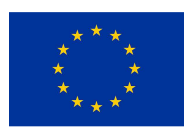

DISCLAIMER

This paper reflects only the authors' views and the European Commission is not responsible for any use that may be made of the information it contains.

\section{REFERENCES}

[1] T. Ackermann, Wind power in power systems. 2005.

[2] J. Quintero, V. Vittal, G. T. Heydt, and H. Zhang, "The impact of increased penetration of converter control-based generators on power system modes of oscillation," IEEE Trans. Power Syst., vol. 29, no. 5, pp. 2248-2256, Sep. 2014.

[3] J. A. P. Lopes, C. L. Moreira, and A. G. Madureira, "Defining Control Strategies for MicroGrids Islanded Operation," IEEE Trans. Power Syst., vol. 21, no. 2, pp. 916-924, May 2006.

[4] H. Xin, L. Huang, L. Zhang, Z. Wang, and J. Hu, "Synchronous Instability Mechanism of P-f Droop-Controlled Voltage Source Converter Caused by Current Saturation," IEEE Trans. Power Syst., vol. 31, no. 6, pp. 5206-5207, Nov. 2016.

[5] H. Golpira, H. Seifi, A. R. Messina, and M. Haghifam, "Maximum Penetration Level of Micro-Grids in Large-Scale Power Systems: Frequency Stability Viewpoint," IEEE Trans. Power Syst., vol. 31, no. 6, pp. 5163-5171, Nov. 2016.

[6] J. Rocabert, A. Luna, F. Blaabjerg, and P. Rodríguez, "Control of Power Converters in AC Microgrids," IEEE Trans. Power Electron., vol. 27, no. 11, pp. 4734-4749, Nov. 2012.

[7] J. Liu, Y. Miura, and T. Ise, "Comparison of Dynamic Characteristics Between Virtual Synchronous Generator and Droop Control in Inverter-Based Distributed Generators," IEEE Trans. Power Electron., vol. 31, no. 5, pp. 3600-3611, May 2016.

[8] H. W. Dommel, "Digital Computer Solution of Electromagnetic Transients in Single-and Multiphase Networks," IEEE Trans. Power Appar. Syst., vol. PAS-88, no. 4, pp. 388-399, 1969.

[9] P. Kundur, N. J. Balu, and M. G. Lauby, Power system stability and control. McGraw-Hill, 1994.

[10] J. C. G. De Siqueira, B. D. Bonatto, J. R. Martí, J. A. Hollman, and H. W. Dommel, "A discussion about optimum time step size and maximum simulation time in EMTP-based programs," Int. J. Electr. Power Energy Syst., vol. 72, pp. 24-32, 2015.

[11] D. Ramasubramanian, Z. Yu, R. Ayyanar, V. Vittal, and J. M. Undrill, "Converter Model for Representing Converter Interfaced Generation in Large Scale Grid Simulations," IEEE Trans. Power Syst., pp. 1-1, 2016.

[12] A. C. Antoulas, D. C. Sorensen, and S. Gugercin, "A survey of model reduction methods for large-scale systems," Am. Math. Soc., vol. 280, pp. 1-28, 2006.

[13] S. Gugercin and A. C. Antoulas, "A Survey of Model Reduction by Balanced Truncation and Some New Results," Int. J. Control, vol. 77, no. 8, pp. 748-766, 2004.

[14] K. E. Willcox and J. Peraire, "Balanced model reduction via the proper orthogonal decomposition," AIAA J., vol. 40, no. 11, pp. 2323-2330, Nov. 2002.

[15] A. C. Antoulas and D. C. Sorensen, "Approximation of Large-Scale Dynamical Systems: An Overview," Int. J. Appl. Math. Comput. Sci., vol. 11, no. 5, pp. 1093-1121, 2001.

[16] D. Chaniotis and M. A. Pai, "Model Reduction in Power Systems Using Krylov Subspace Methods," IEEE Trans. Power Syst., vol. 20, no. 2, pp. 888-894, 2005.

[17] A. López Ríos and A. R. Messina, "An optimal modal approximation method for model reduction of linear power system models," Int. $J$. Electr. Power Energy Syst., vol. 44, no. 1, pp. 293-300, 2013.

[18] I. J. Perez-Arriaga, G. C. Verghese, and F. C. Schweppe, "Selective Modal Analysis with Applications to Electric Power Systems, Part I: Heuristic Introduction," IEEE Power Eng. Rev., vol. PER-2, no. 9, pp. 29-30, Sep. 1982.

[19] S. D'Arco, J. A. Suul, and O. B. Fosso, "Automatic Tuning of Cascaded Controllers for Power Converters Using Eigenvalue Parametric Sensitivities," IEEE Trans. Ind. Appl., vol. 51, no. 2, pp. 1743-1753, Mar. 2015. 